\title{
Correction to: Changes in Phytoplankton Communities in a Tropical Estuary in the Colombian Caribbean Sea
}

\author{
Noris Córdoba-Mena ${ }^{1}$ - Lennin Florez-Leiva ${ }^{1}$ - Lucia Atehortúa ${ }^{2}$ - Erika Obando ${ }^{2}$
}

Published online: 7 July 2020

(C) Coastal and Estuarine Research Federation 2020

\section{Correction to: Estuaries and Coasts}

https://doi.org/10.1007/s12237-020-00750-z

In the original article there are errors in the data of Fig. $3 \mathrm{~b}$.

Following is the corrected figure.

a)

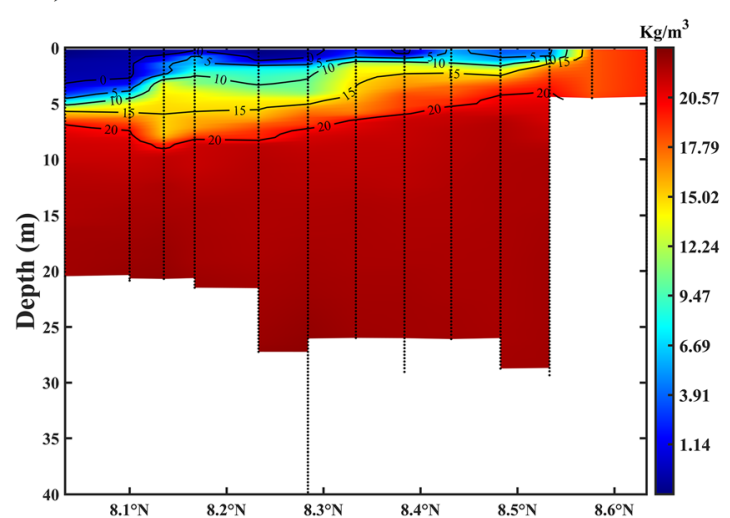

b)

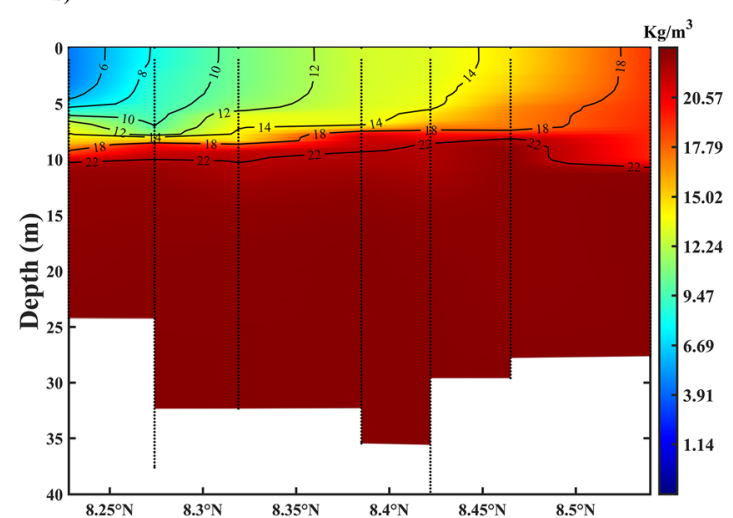

Fig. 3 Vertical profile of estuary potential density anomalies $\left(\sigma_{\mathrm{o}}\right)$ during a rainy season and $\mathbf{b}$ dry season

The online version of the original article can be found at https://doi.org/ 10.1007/s12237-020-00750-Z

Noris Córdoba-Mena noris.cordoba@udea.edu.co

1 Ocean, Climate \& Environment Research Group, Corporación Académica Ambiental, Universidad de Antioquía UdeA, Calle 70 No, 52-21 Medellín, Antioquia, Colombia

2 Biotechnology Research Group, Biology Institute, Universidad de Antioquia UdeA, Calle 70 No, 52-21 Medellín, Colombia 